Journal of Engineering and Applied Sciences 14 (4): 1142-1149, 2019

ISSN: 1816-949X

(C) Medwell Journals, 2019

\title{
Modeling of Air Pollution Caused by Traffic Flows in Manado City, Indonesia
}

\author{
Theo Kurniawan Sendow, Harnen Sulistio, Achmad Wicaksono and Ludfi Djakfar \\ Department of Civil Engineering, Universitas Brawijaya, Malang, Indonesia
}

\begin{abstract}
This study was aimed to determine the level of CO concentration due to traffic flows, know the traffic (vehicle) volume, traffic (vehicle) speed and wind speed, find out the relationship between traffic (vehicle) volume, traffic (vehicle) speed, wind speed and $\mathrm{CO}$ concentration using a regression model as well as examine the parameters influencing air pollution due to traffic flows. The primary data used in this study were the sample data of $\mathrm{CO}$ tested directly in the field and the sampling was done using Ecoline 6000 gas analyzer tool. The research sites covered, the segment of Sam Ratulangi Street in Manado representing the street locations with many multi-rise buildings and high building density, the segment of Ahmad Yani Street in Manado representing the street locations with many trees and the segment of Pierre Tendean Street in Manado representing the street locations with open areas (beachsides). In this modeling, the independent variables were the total traffic volume, the average traffic speed as well as the wind speed and direction. The dependent variable was Carbon monoxide $(\mathrm{CO})$ with increased concentrations. Using the three independent variables, there were total 7 variable combinations used. Then, the obtained model was validated using the surveyed data. The maximum vehicle volume was $4,281.60 \mathrm{pcu} / \mathrm{h}$ (pcu = passenger car unit) and the maximum vehicle speed was $32 \mathrm{~km} / \mathrm{h}$. Meanwhile, the maximum wind speed generated was $7.5 \mathrm{~km} / \mathrm{h}$ and the maximum level of air pollution $(\mathrm{CO})$ was $12.86 \mathrm{ppm}$ $(\mathrm{ppm}=$ part per million). In this study, it was obtained the best model for each of the three locations. The results showed that the air pollution (CO) level of street locations with low wind speed such as Sam Ratulangi Street which is a closed area with many multi-rise buildings and high building density was much higher than that of street locations with many trees growing in the median of streets with a distance of $1 \mathrm{~m}$ from the edge of street pavement and also higher than that of street locations with open areas (beachsides). This is because a higher wind speed can disseminate or divide the concentration level of air pollution $(\mathrm{CO})$ to various places. Air pollution control covers three stages namely the prevention, countermeasure and recovery of air quality.
\end{abstract}

Key words: $\mathrm{CO}$ pollution, model, speed of vehicle traffic volume, wind speed, street, distance

\section{INTRODUCTION}

Problems of urban transport generally include traffic congestion or jam, parking, public transport, pollution and traffic order issues. The major contributor to air pollution in urban areas comes from the transport sector in which more than $70 \%$ of air pollution problems in major cities coming from motor vehicles.

The rapid development of motor vehicle technology both in terms of quantity and quality is followed by a drastic increase in energy consumption (Benson, 1984). On the other hand, energy consumption in the transport sector is the major contributor to air pollution (Downs, 2004). Air pollution caused by exhaust gas emissions resulting from motor vehicles will decrease air quality and endanger human health.

The congestion of motor vehicles gives negative impacts of air pollution. The use of fuel oil as propulsion for vehicles, engine ventilation systems and above all, the exhaust gas emissions coming out from vehicle mufflers as the result of fuel combustion (mixing hundreds of gases and aerosols) are the main causes of the release of various polluters (DEFRA., 2003).

This study was aimed to determine the level of $\mathrm{CO}$ concentration due to traffic flows, know the traffic (vehicle) volume, traffic (vehicle) speed and wind speed, find out the relationship between traffic (vehicle) volume, traffic (vehicle) speed, wind speed and $\mathrm{CO}$ concentration using a regression model as well as examine the parameters influencing air pollution due to traffic flows. Based on this matter, it was necessary to do a "Modelling of air pollution caused by traffic flows in Manado city".

The primary data used in this study were the sample data of $\mathrm{CO}$ tested directly in the field and the sampling was done using Ecoline 6000 gas analyzer tool. The other primary data required were related to the traffic volume and vehicle speed. The data were obtained from the direct

Corresponding Author: Theo Kurniawan Sendow, Department of Civil Engineering, Universitas Brawijaya, Malang, Indonesia 
measurements in the field, i.e., at the same points where the CO gas sampling took place. To make easy the traffic flow calculation at the sampling points, a measurement instrument of traffic counter was used.

In this modeling, the independent variables were the total traffic volume, the average traffic speed as well as the wind speed and direction. Meanwhile, the dependent variable was Carbon monoxide (CO) with increased concentrations. Using the three independent variables, there were total 7 variable combinations used. The obtained model was then validated using the surveyed data. The obtained data might also be tested truthfully using chi-square method and t-test. Based on the regression model, there were found several parameters influencing air pollution due to traffic flows. The parameters were then examined one by one to determine the tendency toward increased air pollution. By conducting a sensitivity test on these parameters, it can be known how far the relationship between these parameters and increased concentration of air pollution.

Traffic volume, traffic speed, wind direction and wind speed can determine the level of $\mathrm{CO}$ concentration. Therefore, the higher increase in freight transport traffic flows will directly cause air pollution in the street environment where the transports pass. Furthermore, traffic density will also cause a decrease in the air or environmental quality due to exhaust gas emissions of motor vehicles coming out from the vehicle mufflers. In obtaining the impacts of the street-environmental pollution, this study was conducted to determine the $\mathrm{CO}$ concentration of traffic flows, know the traffic volume, vehicle speed and wind speed, find out the relationship between traffic (vehicle) volume, traffic (vehicle) speed, wind speed and $\mathrm{CO}$ concentration using a regression model as well as examine the parameters influencing air pollution due to traffic flows. Grounding by this, it was necessary to do a "Modelling of air pollution caused by traffic flows in Manado city". In this modeling, the independent variables consisted of the vehicle (traffic) volume, vehicle composition, vehicle (traffic) speed, wind speed, wind direction and the height and area of surrounding buildings. Meanwhile, the dependent variable was the increased level of $\mathrm{CO}$ gas concentration tested directly in the field. Based on the description above, the statements of problems of this study are as follows:

- What is the characteristic of air pollution caused by traffic flows on the main road segments of Manado city?

- How is the model of air pollution caused by traffic flows on the main road segments of Manado city?

- What is the recommendation (Action program) to reduce air pollution caused by traffic flows?
Scope and limitation: The scope and limitation of this study on the "Modelling of air pollution caused by traffic flow in Manado city" are as follows: the survey was conducted in the administrative area of Manado city. Primary data used were the sample data of $\mathrm{CO}$ tested directly in the field, i.e., at several observation points in Manado city.

Only CO concentration was discussed, instead of other pollutant gases. The method used for the determination of $\mathrm{CO}$ gas was turbidimetric method. Other primary data required were traffic volume and vehicle speed. These data were obtained from direct measurements in the field, i.e., at the same points where CO gas sampling took place.

To make easy the traffic volume calculation at the sampling points, a measurement instrument of traffic counter was used. Measurement of vehicle speed was performed using a speed gun tool. Using this tool, the speed of vehicles moved simultaneously (in cluster/Platoon) would be measured according to the leading vehicle of each cluster/Platoon as the representative vehicle speed.

Measurement of wind direction was conducted using a compass with respect to the direction of vehicle fumes or cigarette smoke using threads embedded in woods and plant leaves around the measuring site. Measurement of wind speed used Intelligent Meter tool. From the data processing above, it was expected to form a model stating the relationship between traffic (vehicle) volume, traffic (vehicle) speed, wind direction, wind speed and $\mathrm{CO}$ concentration resulted in accordance with the equation form in which the correlation value was close to 1 .

In this modeling, the independent variables were the total traffic (vehicle) volume, the average traffic (vehicle) speed and the wind speed and direction. The dependent variable was the increased concentration of Carbon monoxide (CO) gas. Using the three independent variables, there were total 7 variable combinations.

The obtained model was then validated using the surveyed data. The obtained data might also be tested truthfully using chi-square method and t-test. Based on the regression model, there were found several parameters influencing air pollution due to traffic flow. The parameters were then examined one by one to determine the tendency toward increased air pollution. By conducting a sensitivity test on these parameters, it can be known how far the relationship between these parameters and increased concentration of air pollution. The sensitivity test on the model of air pollution caused by traffic flows on the main road segments of Manado city.

Objectives: Grounding on the statements of problems, the objectives of this study are as follows: to know the characteristic of the traffic (vehicle) volume, traffic 
(vehicle) speed, wind speed and air pollution (CO) during rush hours starting from 06.00 WITA until 21.00 WITA; to find out mathematical models of the relationship between traffic (vehicle) volume, traffic (vehicle) speed, wind speed, wind direction and the level of air pollution (CO); to propose recommendation (Action program) for reducing air pollution due to traffic flows.

Significance: The existence of this study is expected to provide benefits as follows: to establish a model of air pollution caused by traffic flows in Manado city; to recommend the handling of air pollution ( $\mathrm{CO}$ concentration) as a result of traffic flows in Manado city. As an input for the government in striving the control of air pollution due to traffic flows and also as an input for the community to support the efforts undertaken by the government in minimizing air pollution.

Contribution: The existence of this study is expected to give contribution as follows: to enrich and complete theoretical and practical studies in the field of transportation engineering, especially on air pollution (CO concentration) as a result of traffic flows. To determine vehicle speed and volume limits, so that, the most minimum air pollution can be reached. As a consideration to the municipal government in determining or choosing an approach to overcome the effects of traffic congestion on the freight transport distribution in Manado city.

Literature review: Here are several previous researches or studies on the relationship between traffic flows and air pollution: Batterman et al. (2010) stating that air pollution related to highway traffic has received attention from researchers and the results of the previous studies have proven the relationship between highway traffic and traffic (vehicle) volume. This study could predict the concentration level of air pollution that might occur.

Brugge et al. (2007) showing that the most vulnerable population in the US who get serious health impacts of air pollution are people living near major regional transport routes and particularly those who live near highways. Studies on dispersion models for the prediction of air pollutant concentrations near highways have resulted in models that use traffic emission, geometric roads and meteorology to predict air pollutant concentrations near the highways. Predictions can be made for carbon monoxide, nitrogen dioxide and suspended particles. Options for air pollution modeling include near intersections, parking lots, elevated highways or highways located in valleys.

Smith with his study on the relationship model between traffic congestion and road traffic emissions as well as its application to urban road networks, finding that: changes in traffic activities, i.e., the distribution of vehicle kilometers (distance) travelled on the network during the day seem to have the greatest impact on predicted traffic emissions, traffic congestion is a crucial issue in $\mathrm{CO}$ and $\mathrm{HC}$ emission modelling. This does not seem to be for NOx emissions in which the basic traffic composition is generally a more important factor (Dowling, 1997). As for the most congested part in urban traffic networks that have been investigated, traffic congestion can result in $\mathrm{CO}$ and $\mathrm{HC}$ emissions that are more than the double estimations, various types of emission models can produce far different results when absolute differences (arithmetic) are considered. However, it can produce a similar result when relative differences (ratios or percentage differences) are not considered.

\section{MATERIALS AND METHODS}

Based on the preliminary surveys, it was determined the research sites covering: the segment of Sam Ratulangi Street, representing the road segments with many buildings. Additionally, the other things to be considered were the building density and the height of buildings in the segment that visually have an influence on the concentration level of CO. The segment of Ahmad Yani Street, representing the road segments with many trees. The segment of Pierre Tendean Street, representing the road segments with open areas (beachsides). Data used in this research in general are as follows:

Primary data: Traffic (vehicle) volumes and compositions, the average speed of each vehicle type, ambient air measurement of $\mathrm{CO}$, measurements of atmospheric characteristics and wind speeds at the research sites.

Secondary data: Road network maps, atmospheric stability table and applicable regulations related to this research.

In addition, the compositions of vehicles passing through these segments varied from motorcycles, private vehicles, public transport vehicles and heavy vehicles. This research was conducted starting on Wednesday, October 1st, 2014 until Thursday, October 3rd, 2014 simultaneously at all the three roads. This research used a descriptive method with the aim to explain the level of air pollution by conducting a survey and observation (direct observation) in the field. The flowchart of this research can be seen in Fig. 1. 


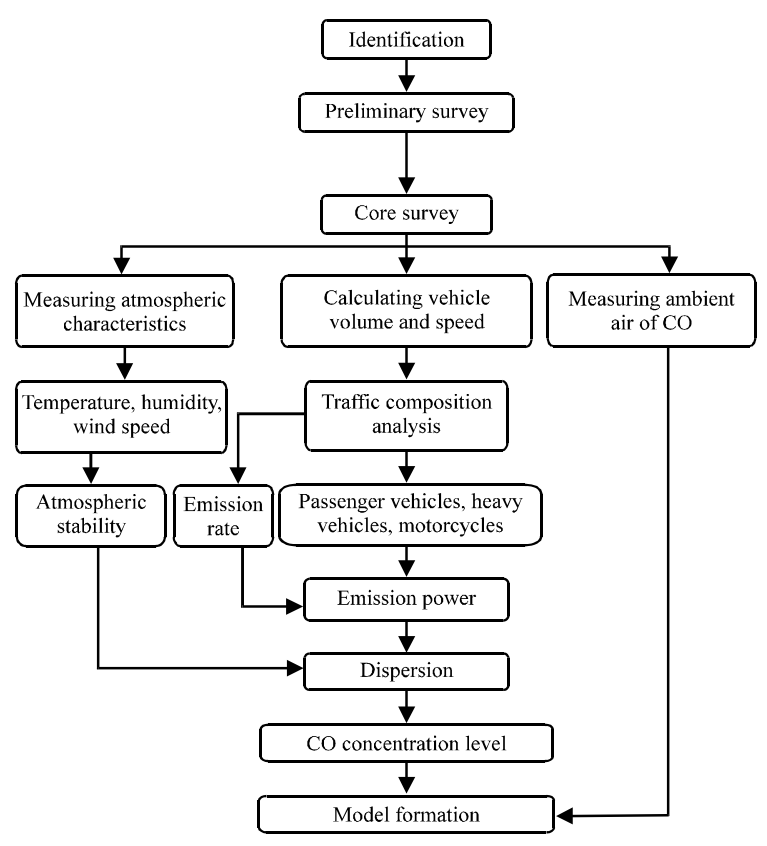

Fig. 1: Research flowchart

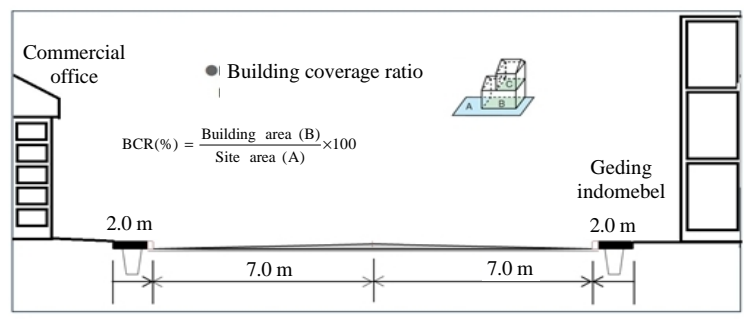

\begin{tabular}{|ll|}
\hline Road name: Sam Ratulangi & Road width: $3.50 \times 4 \mathrm{~m}$ \\
Road type: $4 / 2$-UD & Sidewalk width: $2.0 \mathrm{~m}$ \\
Road length: $\pm 3.78 \mathrm{~km}$ & Curb width: $0.15 \mathrm{~m}$ \\
Road function: Secondary artery & Survey direction: Manado downtown \\
Road status: National & Building coverage ratio: 0.7 \\
& \\
\hline
\end{tabular}

Fig. 2: Cross section of Sam Ratulangi Street in Manado city (Sta $2+000-2+200$ segment)

The objects of this research were the vehicles (traffic flows) passing through the road segments being studied covering (Fig. 2-7):

- The segment of Sam Ratulangi Street for the road type of 4/2-UD

- The segment of Ahmad Yani Street for the road type of $4 / 2-\mathrm{D}$

- The segment of Pierre Tendean for the road type of $4 / 2-U D$

As the samples, the traffic flows were surveyed for 3 days starting at $06.00-19.00$ WITA. The timing of this

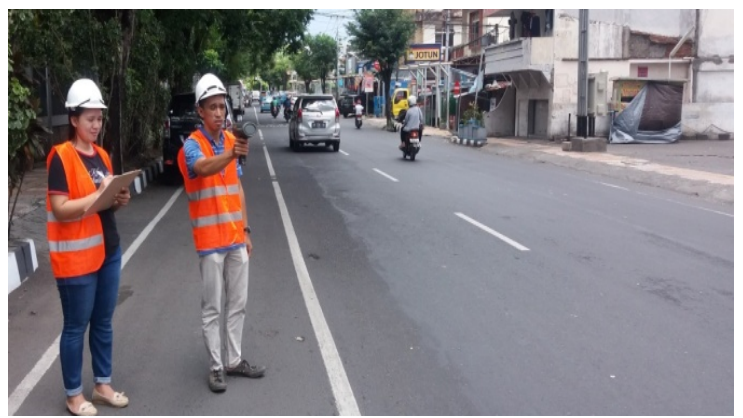

Fig. 3: Documentation of Sam Ratulangi Street in Manado city (Sta $2+000-2+200$ segment)

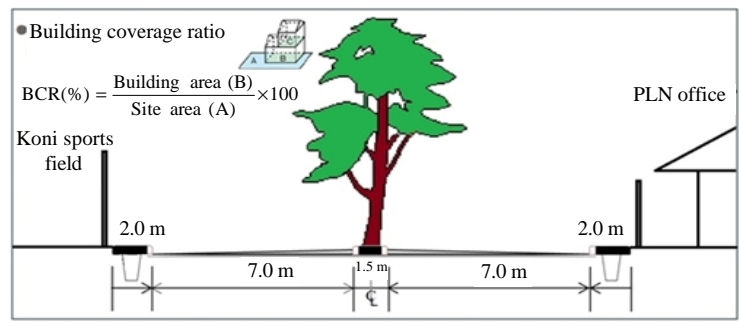

Road name: Ahmad Yani

Road type: 4/2-D

Road length: $\pm 1.75 \mathrm{~km}$

Road function: Secondary artery

Road status: National
Road width: $14.0+1.5 \mathrm{~m}$ Median width: $1.5 \mathrm{~m}$ Sidewalk width: $1.7 \mathrm{~m}$ Curb width: $0.2 \mathrm{~m}$ Building coverage ratio: 0.2
Fig. 4: Cross section of Ahmad Yani Street in Manado city (Sta 0+500- 0+700 Segment)

(a) (b)

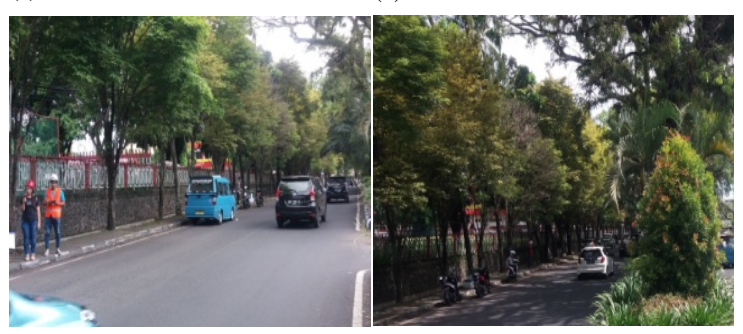

Fig. 5: Documentation of Ahmad Yani Street in Manado city (Sta $0+500-0+700$ segment)

research began on Wednesday, October 1st, 2014 until Thursday, October 3rd, 2014 simultaneously at all the three road segments.

This research was conducted simultaneously for surveying the traffic (vehicle) volumes, traffic (vehicle) speeds, wind speeds and $\mathrm{CO}$ pollution. Along with surveying the volumes of the traffics (vehicles) passing through the road segments, it was also conducted several surveys regarding the measurements of vehicle speeds, 


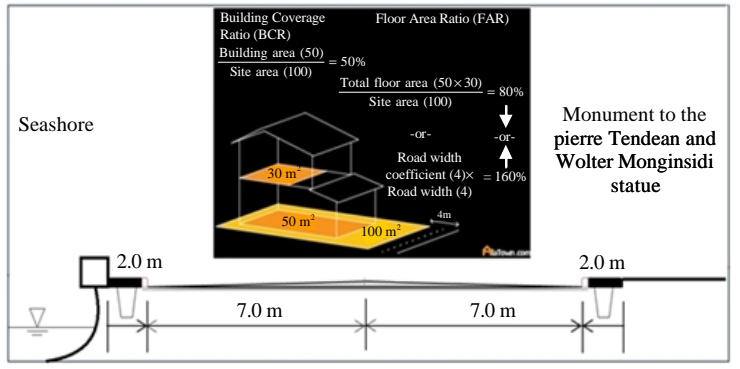

Road name: Sam Ratulangi

Road type: 4/2-UD

Road length: $\pm 3.78 \mathrm{~km}$

Road function: Secondary artery

Road status: National

\begin{abstract}
Road width: $3.50 \times 4 \mathrm{~m}$
Sidewalk width: $2.0 \mathrm{~m}$

Curb width: $0.15 \mathrm{~m}$

Survey direction: Manado downtown Building coverage ratio: 0.2
\end{abstract}

Fig. 6: Cross section of Pierre Tendean Street in Manado city (Sta $0+000-0+200$ segment)

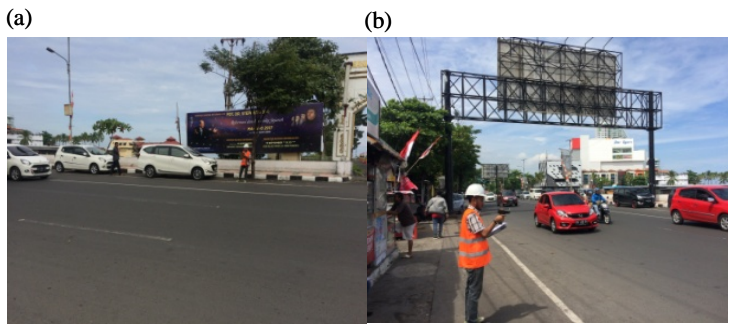

Fig. 7: Documentation of Pierre Tendean Street in Manado city (Sta $0+000-0+200$ segment

ambient air pollutant (CO), atmospheric characteristics and wind speeds. Equipment used in this research is divided into several parts as follows.

Traffic volume measurement instruments: Traffic flow measurements in this research covered traffic (vehicle) volumes and compositions as well as the average speed of each vehicle type. For these measurements, there were several assistant instruments or tools used to collect data in the field (see the following figure) including hand tally counter, survey forms, stationery, length meter and speed gun (radar meter) (Fig. 8).

The measurement of the ambient air pollutant (CO) was conducted in the locations where the traffic flow measurements were also done. The ambient air pollutant (CO) measurement consisted of two parts namely $\mathrm{CO}$ sampling in the air using Ecoline 6000 gas analyzer tool (Fig. 9) and the sampling of temperature, humidity and wind speed using intelligent meter tool (Fig. 9).

Wind speed measurement instrument: Figure 10 shows the wind speed measurement instrument.

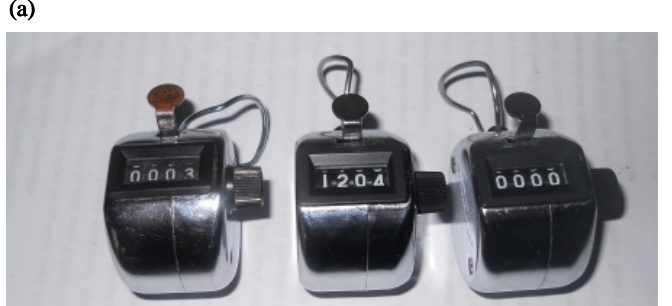

(b)

(c)

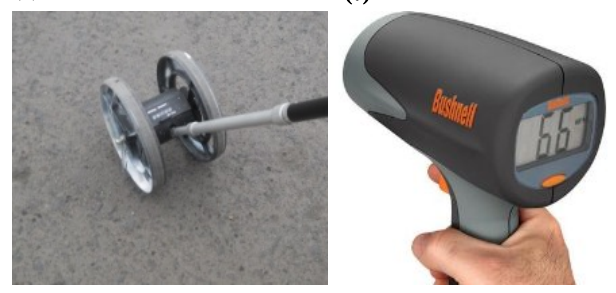

Fig. 8: Instruments used in traffic flow measurement

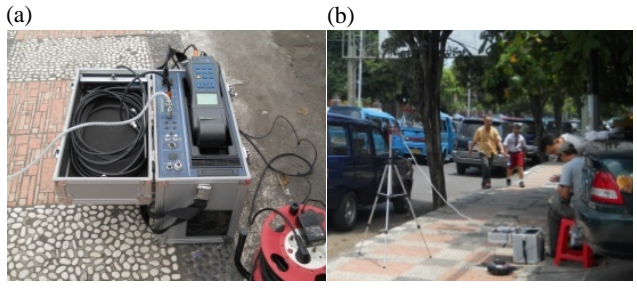

Fig. 9: Measurement of ambient air pollutant (CO) using Ecoline 6000 gas analyzer

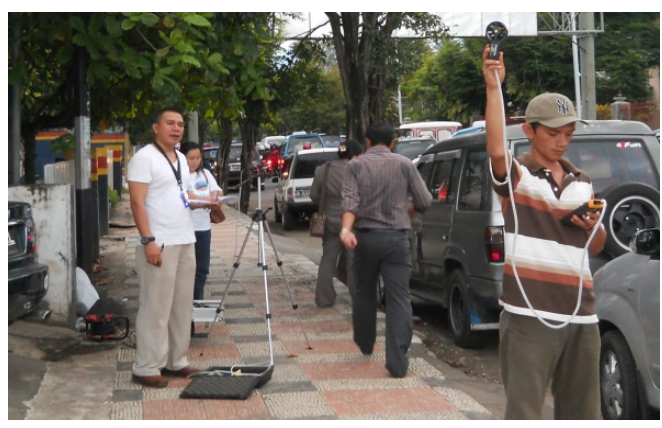

Fig. 10: Measurement of atmosphere characteristics using intelligent meter

\section{RESULTS AND DISCUSSION}

Characteristics of vehicle volume, vehicle speed, wind speed and air pollution (CO): Characteristics of air pollution (CO) in pcu (passenger car unit) and $\mu \mathrm{g} / \mathrm{m}^{3}$ can be seen in Table 1-3 and Fig. 11.

Mathematical model of relationship between vehicle volume, vehicle speed, wind speed and air pollution (CO) level: The models of the relationship between 


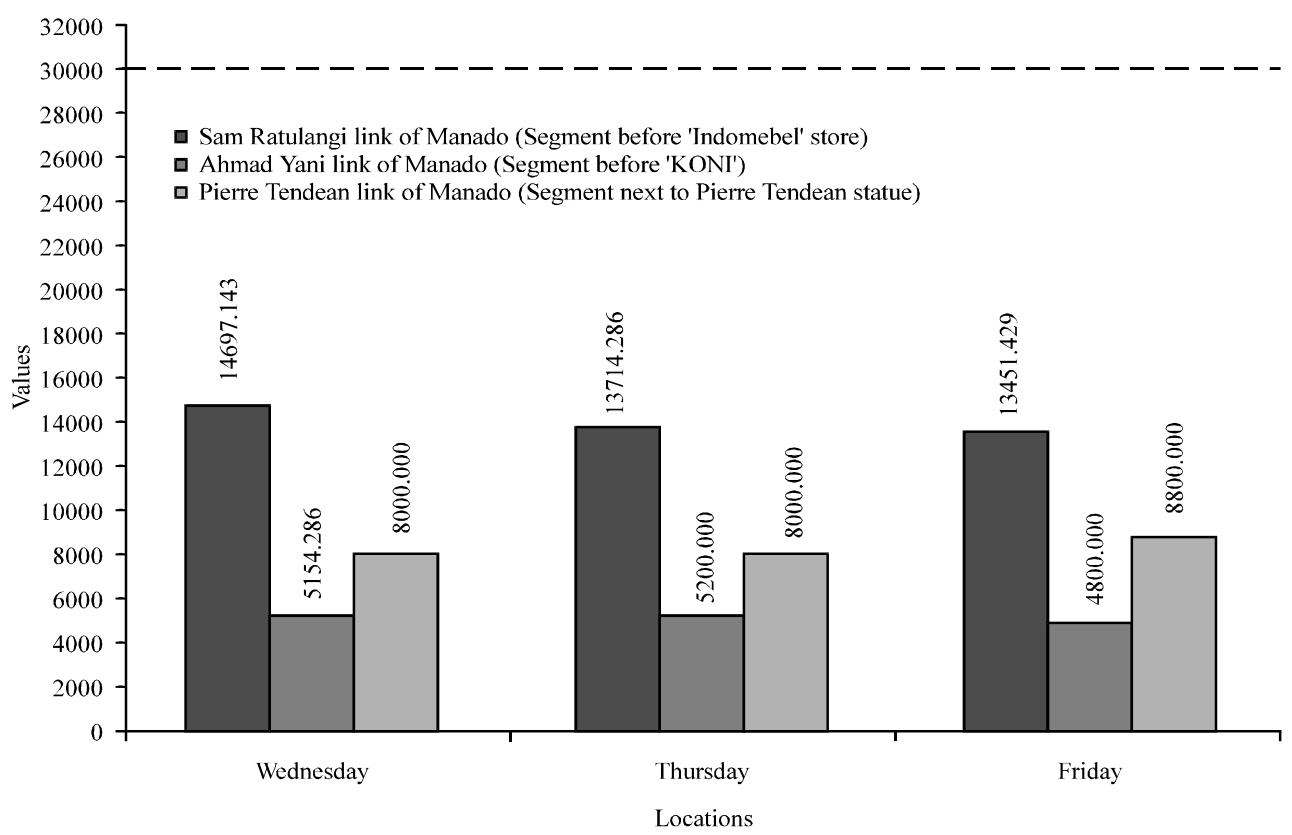

Fig. 11: CO pollution characteristics in pcu and $\mu \mathrm{g} / \mathrm{m}^{3}$ in the three locations (National ambient air quality standard)

Table 1: CO pollution characteristics in pcu and $\mu \mathrm{g} / \mathrm{m}^{3}$ in both traffic flow ways of Sam Ratulangi Street segment in Manado at rush hours

\begin{tabular}{lllll}
\hline & \multicolumn{2}{l}{ CO pollution $(\mathrm{pcu})$} & \multicolumn{2}{l}{ CO pollution $\left(\mu \mathrm{g} / \mathrm{m}^{3}\right)$} \\
\hline Days & Max & Min & Max & Min \\
\hline Wednesday & $16.50-16.55$ & $08.55-09.00$ & $16.50-16.55$ & $08.55-09.00$ \\
& 12.86 & 9.13 & 14697.1429 & 10434.2857 \\
\multirow{2}{*}{ Thurs day } & $08.10-08.15$ & $18.50-18.55$ & $08.10-08.15$ & $18.50-18.55$ \\
& 12.00 & 9.57 & 13714.2857 & 10937.1429 \\
Friday & $07.55-08.00$ & $06.15-06.20$ & $07.55-08.00$ & $06.15-06.20$ \\
& 11.77 & 8.03 & 13451.4286 & 9177.1429 \\
\hline
\end{tabular}

Table 2: CO pollution characteristics in pcu and $\mu \mathrm{g} / \mathrm{m}^{3}$ in both traffic flow ways of Ahmad Yani Street segment in Manado at rush hours

\begin{tabular}{lllll}
\hline & CO pollution $(\mathrm{pcu})$ & \multicolumn{2}{l}{ CO pollution $\left(\mu \mathrm{g} / \mathrm{m}^{3}\right)$} \\
Days & Max & Min & Max & Min \\
\hline \multirow{2}{*}{ Wednesday } & $11.50-11.55$ & $06.00-06.05$ & $16.50-16.55$ & $08.55-09.00$ \\
& 4.51 & 3.50 & 5154.2857 & 4000.0000 \\
Thurs day & $10.35-10.40$ & $08.00-08.05$ & $08.10-08.15$ & $18.50-18.55$ \\
& 4.55 & 3.41 & 5200.0000 & 3897.1429 \\
Friday & $16.55-17.00$ & $12.05-12.10$ & $07.55-08.00$ & $06.15-06.20$ \\
& 4.20 & 3.41 & 4800.0000 & 3897.1429 \\
\hline
\end{tabular}

weed speeds $(\mathrm{km} / \mathrm{h})$ as ' $\mathrm{y}$ ' and $\mathrm{CO}$ pollution (pcu) as ' $\mathrm{x}$ ' in the three road segments surveyed is as follows:

- The survey conducted in the segment of Sam Ratulangi Street on Wednesday: $\mathrm{Y}=8.568859518+$ $-0.3738 . \mathrm{X}$

- The survey conducted in the segment of Sam Ratulangi Street on Thursday: $\mathrm{Y}=8.425089261+$ $-0.3674 . \mathrm{X}$

- The survey conducted in the segment of Sam Ratulangi Street on Friday: $\mathrm{Y}=8.342364932+$ $-0.3663 . \mathrm{X}$
Table 3: CO pollution characteristics in pcu and $\mu \mathrm{g} / \mathrm{m}^{3}$ in both traffic flow directions of Pierre Tendean Street segment in Manado at rush hours

\begin{tabular}{lllll}
\multicolumn{4}{c}{ hours } \\
& CO pollution (pcu) & \multicolumn{2}{l}{ CO pollution $\left(\mu \mathrm{g} / \mathrm{m}^{3}\right)$} \\
\cline { 2 - 4 } Days & Max & Min & Max & Min \\
\hline Wednesday & $10.10-10.15$ & $06.00-06.05$ & $16.50-16.55$ & $08.55-09.00$ \\
& 7.00 & 3.96 & 8000.0000 & 4525.7143 \\
Thursday & $10.15-10.20$ & $18.10-18.15$ & $08.10-08.15$ & $18.50-18.55$ \\
& 7.00 & 4.07 & 8000.0000 & 4651.4286 \\
Friday & $14.35-14.40$ & $15.20-15.25$ & $07.55-08.00$ & $06.15-06.20$ \\
& 7.70 & 4.40 & 8800.0000 & 5028.5714 \\
\hline
\end{tabular}

Survey of 2015

- The survey conducted in the segment of Ahmad Yani Street on Wednesday: $\mathrm{Y}=8.372215959+-0.3434$.X

- The survey conducted in the segment of Ahmad Yani Street on Thursday: $\mathrm{Y}=8.255204755+-0.3322$.X.

- The survey conducted in the segment of Ahmad Yani Street on Friday: $\mathrm{Y}=8.225812868+-0.3359 . \mathrm{X}$

- The survey conducted in the segment of Pierre Tendean Street on Wednesday: $\mathrm{Y}=9.359479083+$ $-0.463898 . \mathrm{X}$

- Survey conducted in the segment of Pierre Tendean Street on Thursday: $\mathrm{Y}=8.970369268+-0.4089 . \mathrm{X}$

- The survey conducted in the segment of Pierre Tendean Street on Friday: $Y=8.965122306+-$ 0.4215.X

On the other hand, the model of the relationship between traffic (vehicle) volume, traffic (vehicle) speed, wind speed and the level of air pollution (CO) is as follows: for the surveys conducted in the segment of Sam Ratulangi Street representing street locations with many 
high-rise buildings and high building density, the best model occurred on Wednesday in which it was obtained: $\mathrm{Y}=6.9457+0.0026 . \mathrm{X}_{1}+8.39227 \mathrm{E}-17 . \mathrm{X}_{2}+4.46169 \mathrm{E}-15 . \mathrm{X}_{3}$ with the $\mathrm{R}^{2}$ value of 0.999999960 and the smallest regression constant of 6.9457 .

For the surveys conducted in the segment of Ahmad Yani Street representing street locations with many trees, the best model occurred on Wednesday in which it was obtained: $\mathrm{Y}=3.271452678+0.001087609 . \mathrm{X}_{1}+-0.0046 . \mathrm{X}_{2}$ with the $\mathrm{R}^{2}$ value of 0.974210486 and the smallest regression constant of 3.271452678.

For the surveys conducted in the segment of Pierre Tendean Street representing street locations with open areas (beachsides), the best model occurred on Wednesday in which it was obtained: $\mathrm{Y}=3.193045646+0.001060108 . \mathrm{X}_{1}+0.00029 . \mathrm{X}_{2}$ with the $\mathrm{R}^{2}$ value of 0.946611656 and the smallest regression constant of 3.193045646 .

Validation of the mathematical model of the relationship between traffic (vehicle) volume, traffic (vehicle) speed, wind speed and the level of air pollution (CO) was carried out for the survey located in the segment of Sam Ratulangi Street. Based on the results of the survey located in the segment of Sam Ratulangi Street on Thursday at $18.50-18.55$, there was a minus difference in which the air ambient measurement result was smaller than the calculation result. Conditions of such a larger calculation result can be caused by several factors as follows: wind speed data collection and atmospheric stability determination are not in accordance with the conditions in the location.

In performing the sampling of wind speed, it is possible that the measurement is undertaken when the wind speed is low, so, the CO concentration becomes high.

In addition, less appropriate determination of atmospheric stability may also be the cause. Determining the atmospheric stability, other than by wind speed, is based on cloud conditions at that time. Moreover, at the time of collecting cloud condition data, it is also possible that only a little cloud can be seen so that the stability of A-B is taken. Meanwhile, due to changes in the atmosphere, the cloud condition can seem clear or bright so that the stability of A should be chosen. Thus, the atmospheric conditions that change so quickly and not stable over time can be the cause.

Recommendation (Action program) in reducing air pollution caused by traffic flows: Based on the survey results, the air pollution $(\mathrm{CO})$ level of areas with low wind speeds such as on Sam Ratulangi Street where the area is a closed area with high-rise buildings and high building density was much higher than that of areas with many trees growing in the median of streets with a distance of $1 \mathrm{~m}$ from the edge of street pavement and also higher than that of street locations with open areas (beachsides). This is because a higher wind speed can disseminate or divide the concentration level of air pollution $(\mathrm{CO})$ to various places. Air pollution control covers three stages namely the prevention, countermeasure and recovery of air quality. The prevention stage is done if the pollutant concentration is still below the ambient air quality standard. That is, do not let the countermeasure stage carried out with the intention to keep the air quality that is still below the ambient air quality standard increase to exceed the limit. The control and recovery stages of air quality are done if the pollutant concentration has exceeded the air quality standard threshold so that the strategy undertaken is in relation to the air quality recovery.

Meanwhile, based on the analysis results, the concentration of $\mathrm{CO}$ gas in the observation locations was still below the ambient air quality standard. Grounding by this fact, the control strategies that need to be done are prevention stages, so that, the concentration of $\mathrm{CO}$ gas does not increase rapidly close to the threshold. To do the control actions, it is necessary to look at the pollutant source, i.e., emissions issued by motor vehicles. Hence, the strategies that need to be done are inspecting and maintaining motor vehicles, increasing the average vehicle speed and limiting the traffic (vehicle) volume.

The air pollution $(\mathrm{CO})$ level of areas with low wind speeds such as on Sam Ratulangi Street where the area is a closed area with high-rise buildings and high building density was much higher than that of areas with many trees growing in the median of streets with a distance of 1 meter from the edge of street pavement and also higher than that of street locations with open areas (beachsides). This is because a higher wind speed can disseminate or divide the concentration level of air pollution $(\mathrm{CO})$ to various places.

\section{CONCLUSION}

Based on the results of this study, it was obtained the maximum traffic (vehicle) volume of $4,281.60 \mathrm{pcu} / \mathrm{h}$, the maximum traffic (vehicle) speed of $32.00 \mathrm{~km} / \mathrm{h}$, the maximum wind speed of $7.50 \mathrm{~km} / \mathrm{h}$, the maximum air pollution (CO) level of $12.86 \mathrm{ppm}$. The mathematical model of the relationship between traffic (vehicle) volume, traffic (vehicle) speed, wind speed and the level of air pollution (CO) for the segment of Sam Ratulangi Street which represents street locations with many high-rise 
buildings and high building density showed that its best model occurred on Wednesday in which it was obtained: $\mathrm{Y}=6.9457+0.0026 \cdot \mathrm{X}_{1}+8.39227 \mathrm{E}-17 . \mathrm{X}_{2}+4.46169 \mathrm{E}-15 . \mathrm{X}_{3}$ with the value of $\mathrm{R}^{2}$ of 0.999999960 and the smallest regression constant of 6.9457. As for the surveys conducted in the segment of Ahmad Yani Street representing street locations with many trees, the best model occurred on Wednesday in which it was obtained: $\mathrm{Y}=3.271452678+0.001087609 . \mathrm{X} 1+-0.0046 . \mathrm{X} 2$ with the $\mathrm{R}^{2}$ value of 0.974210486 and the smallest regression constant of 3.271452678 . Similarly, the best model of the surveys conducted in the segment of Pierre Tendean Street representing street locations with open areas (beachsides) occurred on Wednesday in which it was obtained: $\mathrm{Y}=$ $3.193045646+0.001060108 . X_{1}+0.00029 . X_{2}$ withthe $R^{2}$ value of 0.946611656 and the smallest regression constant of 3.193045646. The air pollution (CO) level of areas with low wind speeds such as on Sam Ratulangi Street where the area is a closed area with high-rise buildings and high building density was much higher than that of areas with many trees also higher than that of street locations with open areas (beachsides). This is because a higher wind speed can disseminate or divide the concentration level of air pollution ( $\mathrm{CO}$ ) to various places. Air pollution control covers three stages namely the prevention, countermeasure and recovery of air quality.

\section{SUGGESTIONS}

Based on the existing research, we suggest that further research be undertaken using the existing model to be used appropriately by the government in taking the policy of development of road transportation system that also consider about air quality improvement such as through the actions of controlling traffic (vehicle) volume or planting shade trees in order to reduce the level of air pollution (CO).

\section{REFERENCES}

Batterman, S.A., K. Zhang and R. Kononowech, 2010. Prediction and analysis of near-road concentrations using a reduced-form emission/dispersion model. Environ. Health, 9: 1-18.

Benson, P.E., 1984. Caline 4-A Dispersion Model for Predictiong Air Pollutant Concentrations Near Roadways. Vice President of the United States, Washington, DC., USA., Pages: 204.

Brugge, D., J.L. Durant and C. Rioux, 2007. Near-highway pollutants in motor vehicle exhaust: A review of epidemiologic evidence of cardiac and pulmonary health risks. Environ. Health, 6: 1-12.

DEFRA., 2003. Part IV of the environment Act 1995, local air quality management technical guidance. Department for Environment, Food and Rural Affairs, Great Britain, UK.

Dowling, R., 1997. Planning Techniques to Estimate Speeds and Service Volumes for Planning. Vol. 387, National Research Council, Washington DC., USA., ISBN: 9780309060585 , Pages: 88.

Downs, A., 2004. Still Stuck in Traffic: Coping with PeakHour Traffic Congestion. Brookings Institution Press, USA., ISBN: 9780815719298, Pages: 455. 